\title{
A new spectrofluorimetric assay method for vandetanib in tablets, plasma and urine
}

\author{
Hany W Darwish ${ }^{1,2}$ and Ahmed H Bakheit ${ }^{1}$ \\ ${ }^{1}$ Department of Pharmaceutical Chemistry, College of Pharmacy, King Saud University, PO Box 2457 Riyadh, 11451 , Kingdom \\ of Saudi Arabia, ${ }^{2}$ Analytical Chemistry Department, Faculty of Pharmacy, Cairo University, Kasr El-Aini St., Cairo 11562, Egypt \\ *For correspondence: Email: hdarwish75@yahoo.com; Fax: +966114676 220
}

\begin{abstract}
Purpose: To develop a simple and sensitive spectrofluorimetric method for the determination of vandetanib (VDB) in tablets (containing $100 \mathrm{mg}$ of the drug) and biological fluids (spiked human plasma and urine).

Methods: The proposed method is based on examining the intrinsic fluorescence intensity of VDB in acetonitrile at $480 \mathrm{~nm}$ after excitation at $330 \mathrm{~nm}$. Factors affecting fluorescence intensity of the cited drug (VDB), including the influence of $\mathrm{pH}$, diluting solvent and time, were studied and optimized by one factor at a time approach. A calibration curve was constructed by plotting VDB fluorescence intensity at $480 \mathrm{~nm}$ versus VDB concentrations in $\mathrm{ng} \mathrm{mL}^{-1}$. The method was validated according to the recommendations of International Conference on Harmonisation (ICH) for validation of the analytical procedures

Results: The linearity range of the method was $20-600 \mathrm{ng} \mathrm{mL}^{-1}$, with limits of quantification (LOQ) and of detection (LOD) of 30.45 and $10.05 \mathrm{ng} \mathrm{mL}^{-1}$, respectively. The adopted method was applied successfully to the quantitation of VDB in pure powder form (100.90 $\pm 0.91 \%)$, laboratory prepared tablets $(97.86 \pm 1.42 \%)$, spiked human plasma (97.97 $\pm 2.36 \%)$ and urine $(97.59 \pm 0.87 \%)$. Comparison of the proposed method with that of liquid chromatography-tandem mass spectrometry showed that there was no significant difference $(p<0.05)$ between the two methods in terms of accuracy and precision.

Conclusion: The proposed method is simple and highly sensitive and, consequently, can be applied to assay VDB in biological samples as well as in dosage form.
\end{abstract}

Keywords: Vandetanib, Spectrofluorimetry, Assay, Validation, Human plasma, Human urine, Dosage forms

Tropical Journal of Pharmaceutical Research is indexed by Science Citation Index (SciSearch), Scopus, International Pharmaceutical Abstract, Chemical Abstracts, Embase, Index Copernicus, EBSCO, African Index Medicus, JournalSeek, Journal Citation Reports/Science Edition, Directory of Open Access Journals (DOAJ), African Journal Online, Bioline International, Open-J-Gate and Pharmacy Abstracts

\section{INTRODUCTION}

Vandetanib (VDB) is considered one of the novel tyrosine kinase inhibitors (TKIs) that acts by inhibiting numerous receptors of the human cell such as RET-tyrosine kinase, epidermal growth factor receptor and others [1,2]. It is prescribed for treating progressive or symptomatic medullary carcinoma of thyroid glands. The effectiveness of VDB for treating ER negative breast cancers was also suggested by modern preclinical researches [3]. Moreover, VDB could be used solely or in combination with other treatment regime such as chemotherapy or radiotherapy for managing other kinds of tumors $[4,5]$. Consequently, it is expected that VDB will be widely spread as an effective anticancer in the 
near future. The chemical structure of VDB is displayed in Figure 1.<smiles>COc1cc2c(Nc3ccc(Br)cc3F)ncnc2cc1OCC1CCN(C)CC1</smiles>

Figure 1: Chemical structure of vandetanib (VDB)

Establishing simple and sensitive analytical method for quantitation of VDB in different matrices is very important as the therapeutic monitoring of a certain medication (VDB in our case) is relied upon the accurate analysis of this medication. Additionally, understanding the relationship between the concentration level and activity of VDB is crucial for its routine and safe usage by the patients. Spectrofluorimetric analysis characterized by various advantages for instance sensitivity and simplicity and wide availability of instrument in quality control laboratories $[6,7]$. For these advantages, this technique was adopted for developing a unified analytical method for quantitation of VDB in different matrices.

Only a few published articles have been reported for VDB assay in plasma or other biological fluids. These analytical methods included liquid chromatographic methods coupled with; mass spectrometry [8-11], diode array [12] and UV detection [13]. The disadvantages of these methods are complexity, high cost and wasting of time in addition to laborious sample treatment. VDB assay in urine samples was reported by just one liquid chromatographic method coupled with mass spectrometry [9] while there are no previous reports, to the best of our knowledge, regarding the assay of VDB in tablets or pure bulk powder. Thus the aim of the present study was to develop a simple, sensitive and unified analytical method for the assay of VDB in various forms based on the native fluorescence of VDB.

\section{EXPERIMENTAL}

\section{Apparatus}

Fluorescence measurements were performed utilizing a Jasco FP-8200 Fluorescence Spectrometer (Jasco Corporation, Japan) equipped with a xenon lamp (150 W) and quartz cells (one $\mathrm{cm}$ ). Excitation and emission slit widths for both monochromators were adjusted at $5 \mathrm{~nm}$. Quinine sulphate $\left(0.01 \mu \mathrm{g} \mathrm{mL} \mathrm{m}^{-1}\right)$ was utilized for frequent calibration of Jasco FP-8200 Spectrometer and the recorded spectra were transformed to ASCII format using Spectra Manager $\circledR$ software.

\section{Reagents and materials}

All the chemicals used in this study were of analytical reagents grade, and the solvents of HPLC grade.

Vandetanib reference standard (purity $99.5 \%$ ) was purchased from LC Laboratories (MA, USA). Methanol, ethanol (Prolabo, France) and acetonitrile (Sigma-Aldrich Chemie $\mathrm{GmbH}$, Germany). Ultrapure water $\geq 18.2 \mathrm{M} \Omega$ was obtained from a Millipore Milli-Q® UF Plus purification system (Millipore, Bedford, MA, USA). Human plasma was kindly provided by King Khaled University Hospital (King Saud University, Riyadh, KSA). After informed consent was obtained, fasting blood samples were taken and plasma, separated and stored at $-70^{\circ} \mathrm{C}$.

\section{Preparation of standard solutions}

VDB stock solution of $1 \mathrm{mg} \mathrm{mL}^{-1}$ was prepared by dissolving $25 \mathrm{mg}$ of VDB reference standard powder into $25 \mathrm{~mL}$ of acetonitrile in a $25 \mathrm{~mL}$ measuring flask and completing the volume properly by the same solvent. VDB stock solution was further diluted with acetonitrile to yield a working standard solution of $1 \mu \mathrm{g} \mathrm{mL}^{-1}$. The standard solutions were stable for at least 14 days when kept refrigerated at $-4{ }^{\circ} \mathrm{C}$.

\section{Construction of calibration graph}

Different volumes of VDB standard solution were transferred into a series of $5 \mathrm{~mL}$ volumetric flasks and diluted with acetonitrile to yield final concentrations of $20-600 \mathrm{ng} \mathrm{mL}^{-1}$. The contents of the flasks were well mixed and RFI of VDB was measured at $480 \mathrm{~nm}$ after excitation at 330 $\mathrm{nm}$. For generation of calibration curve, RFI at $480 \mathrm{~nm}$ (as y axis) was plotted vs the final VDB concentration in $\mathrm{ng} \mathrm{mL}^{-1}$ (as $\mathrm{x}$ axis) and then the regression equation was calculated.

\section{Assay of VDB tablet samples}

Preparation of tablets of VDB produced in-house (equivalent to $100 \mathrm{mg}$ of the drug) took place through weighing precise amount of powder equivalent to $100 \mathrm{mg}$ VDB and transferring it to a $100 \mathrm{~mL}$ volumetric flask. Acetonitrile $(50 \mu \mathrm{L})$ was then added and the contents were shaken and 
sonicated for 10 and $5 \mathrm{~min}$, respectively. Ultimately the volume was diluted to $100 \mathrm{~mL}$ with acetonitrile to get final concentration of $1 \mathrm{mg} \mathrm{mL}$ 1. This solution was subsequently diluted by acetonitrile for further analysis.

\section{Assay of VDB in human plasma}

Liquid-liquid extraction was used for extraction of VDB from spiked plasma samples. Frozen Plasma samples $\left(-20{ }^{\circ} \mathrm{C}\right)$ were thaw at room temperature before processing. Twenty microliters of standard VDB solutions (at different concentrations of the drug) was spiked into one $\mathrm{mL}$ of free drug human plasma and mixed well for one $\min$ to yield final spiked plasma concentrations of 200,300 and $400 \mathrm{ng} \mathrm{mL}$, respectively. One $\mathrm{mL}$ of $100 \mathrm{mM} \mathrm{NaOH} /$ glycine buffer $(\mathrm{pH} 12)$ was added and the tube was mixed properly for $10 \mathrm{~s}$ using vortex mixer. Five $\mathrm{mL}$ of diethyl ether was added and the solution was vortexed for $30 \mathrm{~s}$ and ultra-centrifuged for 15 $\mathrm{min}$ at $10000 \mathrm{rpm}$ to ensure complete phase separation. Afterwards three $\mathrm{mL}$ of the upper organic layer was taken to glass vials and dried under gentle stream of nitrogen. Ultimately, residue reconstitution took place in acetonitrile and the procedures depicted under "Construction of the calibration graph" were then followed. RFI was determined at $480 \mathrm{~nm}$ after excitation at 330 $\mathrm{nm}$ and the concentration of the drug was calculated by substitution in the corresponding regression equation. A blank plasma sample was treated in a similar way.

\section{Assay of VDB in human urine}

Free drug human urine $(1 \mathrm{~mL})$ was spiked with twenty $\mu \mathrm{L}$ of standard drug solutions (at different concentrations of VDB) to yield concentrations of 15,25 and $75 \mathrm{\mu g} \mathrm{mL}^{-1}$, respectively and mixed for $60 \mathrm{~s}$. Further dilution done by adding thirty $\mu \mathrm{L}$ from the prepared previous solution to a thirty microliters of $100 \mathrm{mM} \mathrm{NaOH} /$ glycine buffer $(\mathrm{pH}$ 12) then the tube was vortexed for $10 \mathrm{~s} .1250 \mu \mathrm{L}$ of diethyl ether was added and the solution was vortexed for $30 \mathrm{~s}$ and ultra-centrifuged for $15 \mathrm{~min}$ at $10000 \mathrm{rpm}$ to assure complete phase separation. Then one $\mathrm{mL}$ of the upper organic layer was transferred into glass vial and dried under a gentle stream of nitrogen. Finally, reconstitution of the residue occurred in acetonitrile and the procedures depicted under "Construction of the calibration graph" were then followed. A blank urine sample was treated similarly. Fluorescence intensity was determined at $480 \mathrm{~nm}$ after excitation at $330 \mathrm{~nm}$ and the VDB concentration was calculated by substitution in its corresponding regression equation.

\section{Data analysis}

Analysis of data was carried out using Microsoft Excel-2007 software. Differences were considered statistically significant at $p<0.05$. The data from fluorescence spectrometer were analyzed using Spectra Manager $®$ software.

\section{RESULTS}

The fluorescence spectra of VDB in acetonitrile is illustrated in Figure 2. VDB, being a native fluorescent molecule, exhibited excitation and emission wavelengths of 330 and $480 \mathrm{~nm}$, respectively.

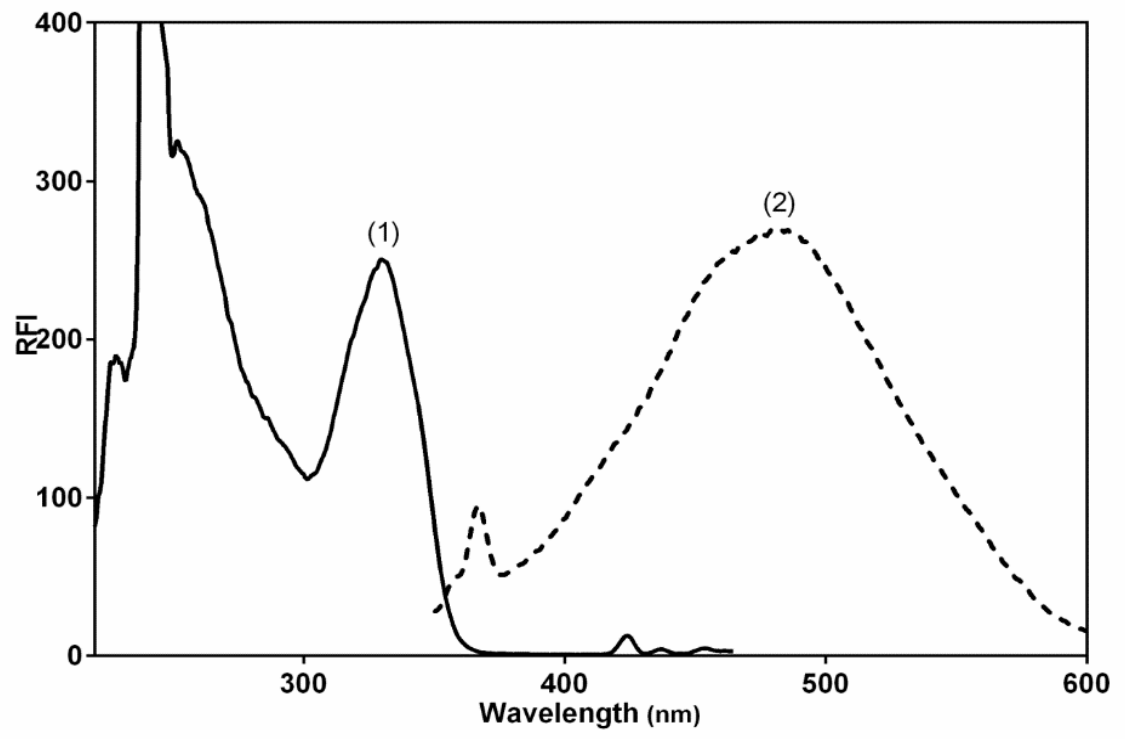

Figure 2: Excitation (1) and emission (2) spectra of VDB (400 $\left.\mathrm{ng} \mathrm{mL}^{-1}\right)$ in acetonitrile 


\section{Effect of $\mathrm{pH}$}

The effect of $\mathrm{pH}$ on the fluorescence intensity of VDB was carefully studied using different buffers covering the $\mathrm{pH}$ range of 2 - 12. It was observed that fluorescence intensity of VDB is not affected by adding any buffer. Thus, no buffer was added in the current work.

\section{Effect of diluting solvent and time}

The effect of addition of various diluting solvents for instance water, short chain alcohols (methanol and ethanol) and acetonitrile on the fluorescence intensity of VDB was evaluated (Figure 3). It was observed that acetonitrile gave the highest response while distinct and sharp decrease in VDB fluorescence intensity was observed on adding other solvents. Accordingly, acetonitrile was utilized for dilution purpose in the current method.

Regarding time effect, it was found that VDB fluorescence intensity developed instantaneously and remained stable for at least $1 \mathrm{~h}$.

\section{Validation results}

Validation of the current spectrofluorimetric method was done in accordance with the recommendations of International Conference on Harmonisation (ICH) for validation of the analytical procedures [14].

\section{Linearity and range}

Calibration curve for VDB assay was constructed under the optimum conditions by plotting VDB fluorescence intensity at $480 \mathrm{~nm}$ against the corresponding VDB concentration. The linearity range was found to be $20-600 \mathrm{ng} \mathrm{mL}-1$ as shown in Table 1.

Statistical analysis [15] of the experimental data displayed high correlation coefficients $(r)$ values (approaching to unity) and low values of; intercept (Sa), slope (Sb), standard deviation of residuals $(\mathrm{S} y / \mathrm{x})$, percentage relative error and percentage relative standard deviation (in Table 1). These values established the linearity of VDB calibration curve.

\section{Limit of quantitation (LOQ) and limit of detection (LOD)}

Limit of quantitation and detection (LOQ and LOD respectively) were computed by measuring; the minimal concentration below which the calibration curve is nonlinear (for LOQ) and the minimal detectable VDB concentration (for LOD). The values of LOQ and LOD were calculated according to Eqs 1 and 2.

$\mathrm{LOD}=3.3 \rho$

$\mathrm{LOQ}=10 \rho$

where $\rho$ is the ratio of standard deviation of the intercept and the slope of regression line. The results are displayed in Table 1.

Maximum concentration of VDB in plasma $\left(\mathrm{C}_{\max }\right)$ reported in the literature [9] is ranged from 117.3 - $131.4 \mathrm{ng} \mathrm{mL}^{-1}$ which is greater than LOQ value (30.45 ng mL ${ }^{-1}$ ) and consequently quantitation of VDB can be done easily by the proposed spectrofluorimetric method.

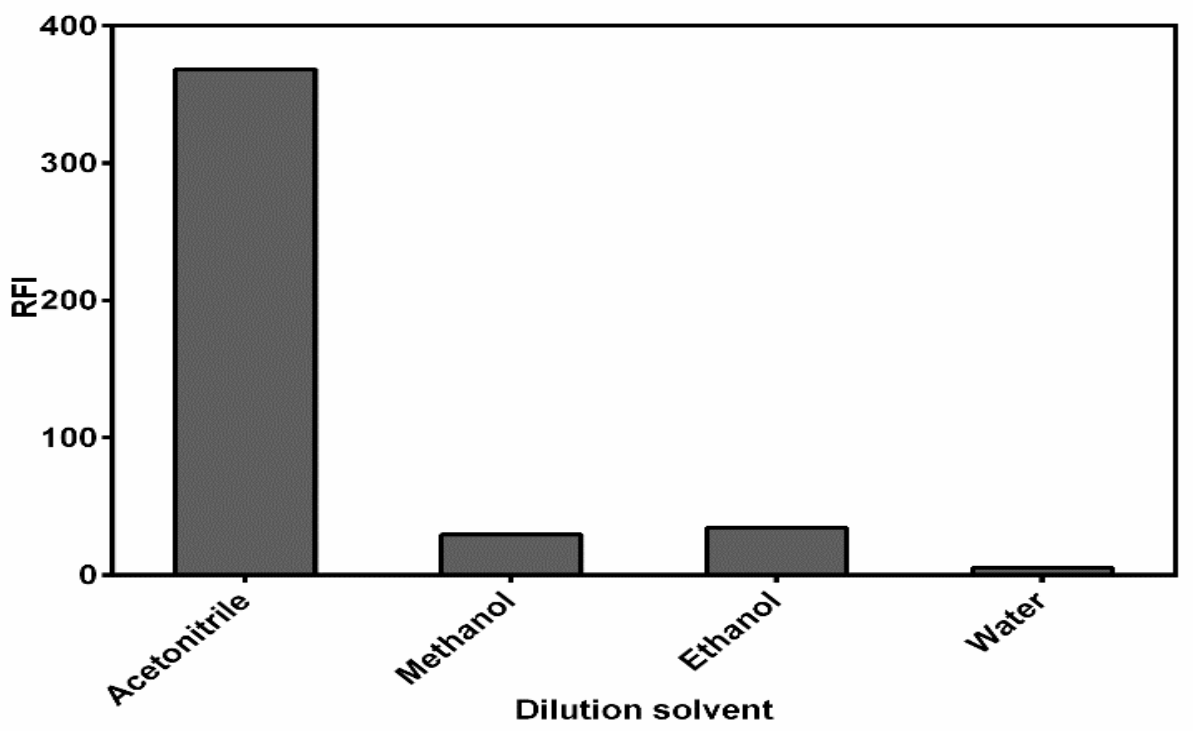

Figure 3: Effect of the diluting solvent on fluorescence intensity of VDB (400 ng mL ${ }^{-1}$ ) 
Table 1: Analytical performance data for spectrofluorimetric determination of VDB

\begin{tabular}{|c|c|}
\hline Parameter & VDB \\
\hline Wavelength $\left[\lambda_{\mathrm{ex}} \lambda_{\mathrm{em}}\right](\mathrm{nm})$ & $330 / 480$ \\
\hline Linearity range $(\mathrm{ng} / \mathrm{mL})$ & $20-600$ \\
\hline Intercept (a) & 7.10 \\
\hline Slope (b) & 0.890 \\
\hline Correlation coefficient $(r)$ & 0.997 \\
\hline S.D. of residuals $\left(S_{y / x}\right)$ & 11.20 \\
\hline S.D. of intercept $\left(\mathrm{S}_{\mathrm{a}}\right)$ & 2.711 \\
\hline S.D. of slope $\left(S_{b}\right)$ & 0.009 \\
\hline$\% \mathrm{RSD}^{\mathrm{a}}$ & 1.337 \\
\hline$\%$ Error $^{\mathrm{D}}$ & 0.696 \\
\hline $\operatorname{LOD}(\mathrm{ng} / \mathrm{mL})^{\mathrm{c}}$ & 10.05 \\
\hline $\mathrm{LOQ}(\mathrm{ng} / \mathrm{mL})^{\mathrm{d}}$ & 30.45 \\
\hline
\end{tabular}

\section{Accuracy and precision}

Table 2 presented results that verify the accuracy and precision of our suggested method. Intra-day and inter-day precision calculation involve the analysis of triplicate sample in one day and three successive days respectively.
Recovery (\% \pm RSD) was utilized for stating intra-day and inter-day precisions. Low values of RSD and about $100 \%$ mean recovery $\%$ demonstrated intra and inter-day precisions of the adopted spectrofluorimetric method (Table 2). Moreover, the comparison achieved between the results of determination of VDB in pure form with the results of VDB determination by the published LC-MS/MS method [8] showed the accuracy of the current proposed method. Computed $\mathrm{F}$ and $\mathrm{t}-$ values were smaller than the tabulated values at $95 \%$ confidence level (Table 3) which in turn confirmed that there is no significant differences between the two methods in terms of accuracy and precision.

\section{Specificity}

By analyzing laboratory prepared tablets of VDB (CAPRELSA $^{\text {TM }}$ tablets), it was clear from the results that the excipients did not interfere with VDB determination which reveal the specificity of the current method (Table 4).

Table 2: Intra-assay and inter-assay precision and accuracy for determination of VDB

\begin{tabular}{|c|c|c|c|c|}
\hline \multirow{2}{*}{$\begin{array}{l}\text { Nominal } \\
\text { conc. } \\
\text { (ng/mL) }\end{array}$} & \multicolumn{2}{|c|}{ Intra-assay } & \multicolumn{2}{|c|}{ Inter-assay } \\
\hline & $\begin{array}{c}\text { Measured conc. } \\
(n g / m L)\end{array}$ & $\begin{array}{c}\text { Recovery }(\% \pm \\
\text { RSD) }\end{array}$ & $\begin{array}{c}\text { Measured conc. } \\
(\mathrm{ng} / \mathrm{mL})\end{array}$ & $\begin{array}{c}\text { Recovery }(\% \pm \\
R S D)^{a}\end{array}$ \\
\hline 40 & 39.59 & $98.97 \pm 1.3$ & 38.51 & $96.27 \pm 1.36$ \\
\hline 100 & 97.52 & $97.52 \pm 1.64$ & 97.19 & $97.19 \pm 1.00$ \\
\hline 200 & 201.11 & $100.55 \pm 1.1$ & 198.73 & $99.36 \pm 1.69$ \\
\hline 400 & 410.34 & $102.58 \pm 0.81$ & 392.98 & $98.24 \pm 0.80$ \\
\hline
\end{tabular}

${ }^{a}$ Mean of three determinations

Table 3: Statistical comparison between analysis results of VDB in pure powder form by proposed spectrofluorimetric method and the reported method [8]

\begin{tabular}{lcc}
\hline Parameter & Proposed method & Reported method[8] \\
\hline Mean & 100.93 & 100.17 \\
SD & 2.458 & 1.355 \\
RSD $\%$ & 2.453 & 1.353 \\
$\mathrm{~N}$ & 9 & 6 \\
Variance & 6.042 & 1.836 \\
F value & $3.291(4.818){ }^{-}$ & \\
T test & $0.758(2.160)$ & \\
\hline${ }^{*}$ Tabulated value at $p=0.05$ &
\end{tabular}

Table 4: Results of the determination of VDB in pure form, laboratory made tablets, human plasma and human urine samples

\begin{tabular}{|c|c|c|c|c|c|c|c|c|c|}
\hline \multirow[b]{2}{*}{ Parameten } & \multicolumn{3}{|c|}{ Pure form } & \multicolumn{2}{|c|}{ Tablets } & \multicolumn{2}{|c|}{ Plasma } & \multicolumn{2}{|c|}{ Urine } \\
\hline & $\begin{array}{c}\text { Amount } \\
\text { taken } \\
\text { (ng/mL) }\end{array}$ & $\begin{array}{c}\text { Amount } \\
\text { added } \\
\text { (ng/mL) }\end{array}$ & $\begin{array}{c}\% \\
\text { Found }\end{array}$ & $\begin{array}{c}\text { Amount } \\
\text { added } \\
\text { (ng/mL) }\end{array}$ & $\begin{array}{c}\% \\
\text { Found }\end{array}$ & $\begin{array}{c}\text { Amount } \\
\text { taken } \\
\text { (ng/mL) }\end{array}$ & $\begin{array}{c}\% \\
\text { Found }\end{array}$ & $\begin{array}{c}\text { Amount } \\
\text { added } \\
\text { (ng/mL) }\end{array}$ & $\%$ Found \\
\hline & 100 & 99.88 & 99.88 & 198.24 & 99.12 & 200 & 99.88 & 15 & 98.17 \\
\hline & 200 & 202.60 & 101.30 & 294.45 & 98.15 & 300 & 95.34 & 25 & 96.59 \\
\hline & 400 & 406.28 & 101.57 & 385.28 & 96.32 & 400 & 98.70 & 75 & 98.00 \\
\hline Mean & & & 100.92 & & 97.86 & & 97.97 & & 97.59 \\
\hline $\pm S D$ & & & 0.91 & & 1.42 & & 2.36 & & 0.87 \\
\hline
\end{tabular}

${ }^{*}$ Tabulated value at $p=0.05$ 


\section{Application of proposed method to assay of VDB tablets}

On application of the proposed method to VDB tablets, recovery of VDB in the tablets was 97.86 $\pm 1.42 \%$ which indicates good accuracy of the proposed procedure (Table 4). By comparing the results of bulk powder analysis in absence and presence of excipients found in VDB tablets, it can be seen that there is no significant difference in the two conditions in terms of accuracy and precision (Table 5). The excipients added are magnesium stearate, microcrystalline cellulose, crospovidone, povidone and calcium hydrogen phosphate dehydrate.

Table 5: Statistical comparison between analysis results of VDB in presence and absence of pharmaceutical excipients by the adopted spectrofluorimetric method

\begin{tabular}{lcc}
\hline \multirow{2}{*}{ Sample no. } & \multicolumn{2}{c}{ VDB recovery (\%) } \\
\cline { 2 - 3 } & Absence & Presence \\
\hline 1 & 99.88 & 99.12 \\
2 & 101.3 & 98.15 \\
3 & 101.57 & 96.32 \\
\hline Mean & 100.92 & 97.86 \\
S.D. & 0.91 & 1.42 \\
Variance & 0.824 & 2.022 \\
Degree of & \multicolumn{2}{|}{} \\
freedom & \multicolumn{2}{|}{} \\
t-test $(2.776)^{*}$ & \multicolumn{2}{c}{3.135} \\
F-test (19) & \multicolumn{2}{c}{2.453} \\
\hline * Tabulated value at $p=0.05$ &
\end{tabular}

\section{Application of proposed method to determination of VDB in human plasma}

The sensitivity of the adopted spectrofluorimetric method allowed us to quantify VDB in spiked human plasma. Maximum concentration of VDB in plasma attained after $6 \mathrm{~h}$ following oral administration [9] where its $C_{\max }$ value was 131.4 $\mathrm{ngmL}^{-1}$ under fasted circumstances ${ }^{[9]}$. Hence, level of VDB in plasma is involved in the linear range of the current procedure (Table 1). Table 5 displayed mean recovery \% and RSD\% of VDB in spiked plasma samples $(97.97 \%, 2.36 \%$ respectively).

\section{Application of proposed method to assay of VDB in urine}

In the first three days, VDB excreted in urine largely unchanged and ranged from $1.9-3.4 \%$ of normal adult dose (300 $\mathrm{mg}$ daily) [9]. Consequently, the range of VDB concentration in urine $\left(1.9-3.4 \mathrm{\mu g} \mathrm{mL}^{-1}\right)$ is above the linear range of the current procedure. Mean recovery and RSD for VDB in urine samples were 97.59, and $0.87 \%$, respectively.

\section{DISCUSSION}

In this study, a unified procedure was proposed for determination of VDB in different matrices including pharmaceutical preparation, human plasma and urine. Upon examination of literature, it was observed that few analytical methods were reported for VDB determination. Accordingly, a simple and sensitive spectrofluorimetric method was developed in the current work for VDB quantitation in these different matrices. Generally, the fluorescence spectrum of a native fluorescent drug composed of two spectra, the first spectrum associated with the excitation behavior of the drug while the other one associated with its emission of the absorbed electromagnetic radiation (EMR). Excitation spectrum is acquired by scanning excitation monochromator and fixing emission monochromator at a certain wavelength. The emission spectrum is acquired similarly, but scanning the emission monochromator and fixing the excitation monochromator at a particular wavelength. Therefore, for a fluorescent drug, two wavelengths are detected where highest response observed in the excitation and emission spectra ( $\lambda_{\mathrm{ex}}$ and $\lambda_{\mathrm{em}}$, respectively).

The principal demand for a drug to produce a fluorescence spectrum is to absorb EMR. VDB displays an excitation wavelength of $330 \mathrm{~nm}$. This is due to absorption of EMR encouraging electron from its ground state to the excited state. The emission spectrum of VDB was then measured (utilizing concentration of $400 \mathrm{ng} \mathrm{mL}^{-1}$ ) keeping the excitation monochromator at $330 \mathrm{~nm}$ and scanning the emission monochromator in the range of $300-600 \mathrm{~nm}$. Highly intense emission peak with maximum at $480 \mathrm{~nm}$ was observed, demonstrating the native fluorescence behaviour of VDB. Then the excitation spectrum was recorded, but now keeping the emission monochromator at $480 \mathrm{~nm}$ and scanning the excitation monochromator to precisely detect $\lambda_{\mathrm{ex}}$ which observed at $330 \mathrm{~nm}$.

Various parameters that may influence fluorescence intensity of VDB were adjusted carefully adopting changing one factor at a time strategy. From the previous results it was clear that the most effective parameter was the diluting solvent. Acetonitrile was chosen for conducting this study as it gave the highest fluorescence intensity. This may be due to alteration of the polarity of the medium which could result in physical interaction between the excited singlet state of the analyte molecules and the solvents molecules. 


\section{CONCLUSION}

The developed spectrofluorimetric method is simple, sensitive and can be applied successfully to VDB quantitation in quality control and clinical laboratories. The method offers several advantages over published chromatographic methods for VDB determination, including simplicity, rapidity and low cost. Additionally, the method is based on measuring the native fluorescence property of VDB and thus, there is no need to use expensive fluorogenic reagents.

\section{DECLARATIONS}

\section{Acknowledgement}

The authors would like to extend their sincere appreciation to Deanship of Scientific Research at the King Saud University for funding this work through Research Group Project no. RGP-322.

\section{Conflict of Interest}

No conflict of interest associated with this work.

\section{Contribution of Authors}

The authors declare that this work was done by the authors named in this article and all liabilities pertaining to claims relating to the content of this article will be borne by them.

\section{REFERENCES}

1. Ciardiello F, Caputo R, Damiano V, Caputo R, Troiani T, Vitagliano $D$, Carlomagno $F$, Veneziani $B M$, Fontanini $G$, Bianco AR. Antitumor effects of ZD6474, a small molecule vascular endothelial growth factor receptor tyrosine kinase inhibitor, with additional activity against epidermal growth factor receptor tyrosine kinase. Clin Cancer Res 2003; 9(4): 1546-1556.

2. Wedge SR, Ogilvie DJ, Dukes M, Kendrew J, Chester R, Jackson JA, Boffey SJ, Valentine PJ, Curwen JO, Musgrove HL. ZD6474 inhibits vascular endothelial growth factor signaling, angiogenesis, and tumor growth following oral administration. Cancer Res 2002; 62(16): 4645-4655.

3. Marangoni E, Hatem R, Labiod D, Chateau-Joubert S, El Botty R, Servely J-L, De Plater L, Bièche I. Vandetanib as a potential new treatment for ER negative breast cancers. Cancer Res 2015; 75(15 Supplement): 1687 1687.

4. Xiao $Y-Y$, Zhan $P$, Yuan D-M, Liu H-B, Lv T-F, Shi $Y$, Song $Y$. Chemotherapy plus vandetanib or chemotherapy alone in advanced non-small cell lung cancer: a meta-analysis of four randomised controlled trials. Clin Oncol 2013; 25(1): e7-e15.

5. Drappatz J, Norden AD, Wong ET, Doherty LM, LaFrankie DC, Ciampa A, Kesari S, Sceppa C, Gerard $M$, Phan $P$. Phase I study of vandetanib with radiotherapy and temozolomide for newly diagnosed glioblastoma. Int J Radiat Oncol Biol Phys 2010; 78(1): 85-90.

6. Aydoğmuş Z, Sarı F, Ulu ST. Spectrofluorimetric determination of aliskiren in tablets and spiked human plasma through derivatization with dansyl chloride. J Fluoresc 2012; 22(2): 549-556.

7. Balwani G, Joseph E, Reddi S, Nagpal V, Saha RN. Rapid, Simple, and Sensitive Spectrofluorimetric Method for the Estimation of Ganciclovir in Bulk and Pharmaceutical Formulations. J Spectrosc 2013; 2013:1-5.

8. Bai F, Johnson J, Wang F, Yang L, Broniscer A, Stewart CF. Determination of vandetanib in human plasma and cerebrospinal fluid by liquid chromatography electrospray ionization tandem mass spectrometry (LCESI-MS/MS). J Chromatogr B Analyt Technol Biomed Life Sci 2011; 879(25): 2561-2566.

9. Martin P, Oliver S, Kennedy S-J, Partridge E, Hutchison $M$, Clarke $D$, Giles $P$. Pharmacokinetics of vandetanib: three phase I studies in healthy subjects. Clin Ther 2012; 34(1): 221-237.

10. Andriamanana I, Gana I, Duretz B, Hulin A. Simultaneous analysis of anticancer agents bortezomib, imatinib, nilotinib, dasatinib, erlotinib, lapatinib, sorafenib, sunitinib and vandetanib in human plasma using LC/MS/MS. J Chromatogr B Analyt Technol Biomed Life Sci 2013; 926: 83-91.

11. Zirrolli JA, Bradshaw EL, Long ME, Gustafson DL. Rapid and sensitive $L C / M S / M S$ analysis of the novel tyrosine kinase inhibitor ZD6474 in mouse plasma and tissues. J Pharm Biomed Anal 2005; 39(3): 705-711.

12. Xiang $S X, W u H L$, Kang $C$, Xie $L X$, Yin $X L$, Gu HW, Yu $R Q$. Fast quantitative analysis of four tyrosine kinase inhibitors in different human plasma samples using three-way calibration-assisted liquid chromatography with diode array detection. J Sep Sci 2015. 38(16): 2781-2788.

13. Lin $H$, Cui D, Cao Z, Bu Q, Xu Y, Zhao Y. Validation of a high-performance liquid chromatographic ultraviolet detection method for the quantification of vandetanib in rat plasma and its application to pharmacokinetic studies. J Cancer Res Ther 2014; 10(1): 84-88.

14. $\mathrm{ICH}$. Validation of Analytical procedures. Methodology (Q2AR1), International Conference on Harmonization; November 1996 and November 2005; USA: Food and Drug Administration; November 1996 and November 2005.

15. Miller JN, Miller JC. Statistics and chemometrics for analytical chemistry: Pearson Education; 2005. 